\title{
AS FORMAS DE EXPRESSÃO DE FUTURO NAS CARTAS DE LEITORAS DA REVISTA FEMININA GLOSS
}

\section{THE FORMS OF EXPRESSION OF FUTURE IN THE READERS LETTERS OF WOMEN MAGAZINE GLOSS}

\section{CLEMPI, Camila Bordonal}

Mestranda no Programa de Pós-Graduação em Linguística e Língua Portuguesa da Universidade Estadual Paulista "Júlio de Mesquita Filho", campus de Araraquara-SP. Bolsista FAPESP, processo n. 2017/16959-6.

\section{BARBOSA, Juliana Bertucci}

Doutorado em Linguística e Língua Portuguesa pela UNESP/Araraquara com estágio PDEE/CAPES na Universidade de Lisboa. Professora Adjunto da Universidade Federal do Triângulo Mineiro (UFTM), Campus de Uberaba-MG. Professora Permanente e Coordenadora Local do Mestrado Profissional em Letras (PROFLETRAS) da UFTM e na UNESP de Araraquara. Líder do Grupo de pesquisas GEVAR (Grupo de Estudos Variacionistas), plataforma CNPq. Coordenadora do PLI/CAPES (Programa de Licenciaturas Internacionais) na UFTM.

\section{RESUMO}

Este trabalho investiga a expressão variável de futuro em cartas de leitoras, extraídas da revista feminina contemporânea Gloss, publicadas no período de 2008 a 2013. Verificamos quais são as diferentes estruturas linguísticas empregadas pelas adolescentes: a forma sintética (futuro simples); a forma perifrástica (verbo IR no presente + infinitivo); a forma perifrástica (verbo IR no futuro + infinitivo) e a forma do presente. Além disso, verificamos se essas diferentes formas de expressão aparecem com a presença ou ausência de adjuntos adverbiais de tempo e se estão relacionadas a valores semânticos modais. Após a seleção e codificação dos dados, analisamos os resultados seguindo a metodologia da teoria variacionista. Como resultado, a perífrase IR no presente + infinitivo e 
o verbo no presente do indicativo (ora como auxiliar modal, ora como principal), mostraram ser os mais produtivos entre as leitoras.

Palavras-chave: Variação Linguística; tempo Futuro; português brasileiro.

\section{ABSTRACT}

This paper investigates the variable expression of the future in reader's letters, extracted from the feminine magazine Gloss, published between 2008 and 2013. We verify the different linguistic structures used by adolescents: the synthetic form (simple future); the periphrastic form (IR in the present + infinitive); the periphrastic form (IR in the future + infinitive) and the form of the present tense. In addition, we verify if these different forms of expression appear with the presence or absence of adverbial time attachments and whether they are related to modal semantic values. After data selection and codification, we analyzed the results following the methodology of the variationist theory. As a result, the periphrasis IR in the present + infinitive and the verb in the present tense (now as modal auxiliary, sometimes as main), have been the most productive among the readers.

Keywords: Linguistic Variation; future tense. brazilian portuguese.

\section{INTRODUÇÃO}

A Teoria da Variação e Mudança (LABOV, 2008 [1972]), ao relacionar língua e sociedade, considera a língua em uso, em uma comunidade de fala real, em uma dada situação concreta de comunicação. Nesse sentido, a língua é vista como dinâmica, variável e heterogênea. Dentre as várias possibilidades de variação na estrutura da língua, nossa pesquisa tem como objetivo analisar as formas de expressão de futuro no Português Brasileiro (daqui em diante PB) contemporâneo.

Conforme atestam alguns estudos (SILVA, 2002; OLIVEIRA, 2006, BARBOSA, 2007), a variação de futuro ocorre principalmente a partir das alternâncias entre a forma sintética (Futuro do Presente do Indicativo) e as forma perifrásticas (verbo IR no presente e no futuro + infinitivo), além da forma do Presente do Indicativo, como observamos em: 
(01)João apresenta uma peça de teatro essa noite.

(02)João apresentará uma peça de teatro essa noite.

(03)João vai apresentar uma peça de teatro essa noite.

(04)João irá apresentar uma peça de teatro essa noite.

Nas sentenças hipotéticas acima, o verbo apresentar, destacado nos trechos, está conjugado em diferentes formas verbais: em (01) encontra-se no Presente do Indicativo, já em (02) no Futuro do Presente do Indicativo, em (03) na forma perifrástica IR no presente + infinitivo e por fim em (04) na forma perifrástica IR no futuro + infinitivo. Apesar das diferenças sintáticas e morfológicas, todas as sentenças expressam tempo futuro.

Nossa proposta é investigar como se dá a expressão variável de futuro nas cartas de leitoras da revista feminina Gloss, publicadas no período de 2008 a 2013. A análise da variação de futuro a partir de uma amostra de escrita, portanto, faz-se produtiva na tentativa de contribuir para as diversas pesquisas de tema semelhante.

Para iniciar nosso trabalho, apresentamos um quadro teórico em que há uma breve discussão sobre as categorias do tempo, bem como as abordagens das Gramática Tradicionais (daqui em diante GT's) e da Linguística para designar o valor temporal futuro - foco desta pesquisa. Além disso, também apresentamos estudos que possuem o mesmo tema que o nosso e que são relevantes para contribuir, seja para comparar ou para fortalecer, nossa análise dos dados. Em sequência, descrevemos os materiais e os métodos ao quais nos propomos a trabalhar. Informamos considerações importantes sobre a revista Gloss e sobre o gênero "carta de leitor". Por fim, apresentamos os grupos de fatores e a análise dos dados.

\section{A CATEGORIA "TEMPO"}

Para obter as diversas informações que temos hoje a respeito da noção de "tempo", foram necessárias diversas pesquisas, realizadas tanto por filósofos, físicos, como também por linguistas.

Santo Agostinho foi um dos filósofos a refletir sobre esta categoria. Baseado nos pressupostos cristãos, Agostinho afirmava que Deus era quem fazia o próprio tempo, nessa concepção o tempo ocorria na mente humana. Assim como a figura católica, Aristóteles também 
desenvolveu teorias que caracterizavam o tempo "como um fenômeno físico, natural" (BARBOSA, 2008, p. 43) e que se construía por meio dos eventos e de suas relações. Já na Física, Newton e Gallileu consideravam o tempo fora dos eventos, fluído e sem relação a algo externo a ele. Posteriormente, Einsten, a partir das ideias de Newton e Gallileu, estabeleceu que a percepção de tempo poderia ser diferente de acordo com os diversos pontos de vista dos observadores (SILVA, 2002).

Na visão de Benveniste (2006 [1989], p. 71-74), a noção de "tempo" compreende diferentes representações. Para ele, há três tipos de tempos: o físico, o cronológico e o linguístico. O primeiro é dado como algo exterior ao homem, algo dado como linear, infinito, segmentável à vontade. Já o segundo, o cronológico, "é a continuidade em que se dispõem em série estes blocos distintos que são os acontecimentos". Por fim, o linguístico é identificável como semelhante aos outros dois tempos, mas "o fato de estar organicamente ligado ao exercício da fala, o fato de se definir e de organizar como função do discurso" o faz singular.

Assim como Benveniste (2006 [1989]), no campo da Linguística, vários outros estudiosos dedicaram-se a caracterizar a noção de "tempo" na língua, como é o caso de Reichenbach (1947). Segundo o teórico, os eventos estão ligados a um indivíduo e a sucessividade ou simultaneidade dos eventos dependem de sua posição. Para Reichenbach (1947), as sentenças enunciadas são representadas por meio do Momento da Fala (MF), Momento do Evento (ME) e Momento de Referência (MR). Tomamos como exemplo a seguinte sentença hipotética:

\section{(05) Maria estudará para a prova.}

Em (05), o MR e o MF ocorrem simultaneamente na linha do tempo, ou seja, o momento em que o indivíduo está situado é o mesmo do enunciado da sentença - de que Maria realizará a ação de estudar. $\mathrm{O} M E$, por sua vez, encontra-se posterior ao MR e ao MF, como o esquema sugere:

$$
\text { (06) } M R=M F ; M R \text { e } M F \neq M E
$$

De acordo com (06), a sentença configura o tempo futuro e transmite o valor de prospecção aos eventos. Silva (2002) ressalta que este tempo está veiculado ao não-agora, ao que vem depois, não tem, pois, uma existência material, é construído a partir de nuances de possibilidade e, por isso, é formado por uma sobreposição modal/ 
temporal. Na próxima seção, discutiremos como linguistas e gramáticos compreendem a questão do futuro no PB.

\section{A EXPRESSÃO VARIÁVEL DE FUTURO NO PORTUGUES BRASILEIRO}

Ao entrarmos em contato com os materiais didáticos e com as GT's, é evidente a restrição prescrita para expressar o tempo futuro, normalmente apresentando apenas as formas conjugadas no Futuro do Presente do Indicativo.

Alguns autores mencionam sucintamente alternativas de uso, como é o caso de Cunha e Cintra (2001, p. 397) que indicam a forma perifrástica IR no presente + infinitivo, na seção destinada aos verbos auxiliares, com a finalidade "de executar a ação, ou a certeza que ela será realizada em um futuro próximo". Cegalla (2008) também aponta a combinação do verbo IR como auxiliar somado ao infinitivo, mas sem qualquer outro comentário sobre a caracterização desse tempo verbal. Já Bechara (2009, p. 214) ainda apresenta o uso do presente para expressar o futuro em verbos pontuais como forma de neutralização, como por exemplo, "ele chega amanhã".

Observamos que nas GT's a variação no emprego das formas linguísticas para expressar tempo futuro não é apresentada de maneira satisfatória, mesmo que reconhecidas algumas formas de expressão de futuro, há a distinção de significado entre elas.

Já os (sócio)linguistas atestam variações no uso da expressão de futuro, seja em pesquisas referentes à escrita ou à fala (cf. SILVA, 2002; OLIVEIRA, 2006; BARBOSA, 2007; OLIVEIRA, 2011). Dentre as variantes, o presente do indicativo e a forma perifrástica IR no presente + infinitivo tornaram-se as mais frequentes atualmente no PB, substituindo a forma sintética de futuro simples.

Silva (2002) em seu trabalho, de cunho quantitativo, chegou a essa conclusão analisando variações da expressão de futuro em ocorrências de fala do PB. Para a montagem do corpus, foram usadas seis horas e meia de gravações aproximadamente, com o intuito de observar os valores temporais/modais e o contexto discursivo em que as formas se configuravam na amostra. $\mathrm{O}$ autor selecionou duas elocuções formais do projeto NURC, onze conversas telefônicas, um diálogo interativo, quatro entrevistas e, programas de TV e rádio.

A forma IR no presente + infinitivo, para Silva (2002), possui um valor de futuro ligado intrinsicamente ao tempo psicológico, muito 
mais do que ao tempo cronológico. A perífrase, nessa perspectiva, ligase à noção de relevância do presente em relação ao tempo futuro, isto é, a realização do evento depende da ação do tempo presente. Além disso, Silva (2002, p. 99) assinala que os contextos discursivos em que a forma perifrástica ocorre são de caráter ideacional, em que locutor e interlocutor "comentam, narram, fazem injunções e predicações".

Já o Presente do Indicativo, de acordo com Silva (2002), é utilizado a fim de expressar um evento futuro em relação a um fato presente. O Futuro do Presente do Indicativo, por sua vez, mostrouse pouco produtivo em sua pesquisa. Cabe ressaltar, também, que o linguista analisou o Futuro do Pretérito Simples e verificou a sua pouca utilização, tendo sido usado apenas em contextos narrativos.

Como resultado do trabalho, Silva (2002) conclui que as formas futurizadas são utilizadas em falas informais espontâneas, enquanto as formas sintéticas de futuro ocorrem em estruturas formulaicas, vista como distantes, imparciais, pouco comuns.

Baseada no estudo acima, Barbosa (2007) realizou uma análise comparativa entre as modalidades escrita e falada da língua, a fim de evidenciar as diferentes formas de expressão de futuro no PB. Para tanto, a autora montou um corpus composto por textos literários, escritos a partir da década de 90, de diferentes modalidades (oratória, romanesca e dramática), representando, respectivamente, o grau máximo da linguagem formal, o grau neutro, e o grau mais espontâneo, aproximado ao da fala. O trabalho, em específico, analisou apenas a literatura oratória.

Na análise, Barbosa (2007) verificou que as formas sintéticas do futuro predominam na oratória, devido ao caráter conservador, ao alto grau de formalidade, à modalização e também à tipologia textual da modalidade. Em conclusão, afirmou que os fatores mencionados "afetam a produtividade das formas futurizadas da língua portuguesa" (BARBOSA, 2007, p. 49).

Outros estudos também abordam a questão da variação de expressão de futuro, como Oliveira (2006, p. 17, grifo do autor), que elenca seis variantes do futuro do PB:

a) a forma de futuro simples ("No próximo mês viajarei para o exterior"); b) a forma de presente ("No próximo mês viajo para o exterior"); c) a forma perifrástica com o verbo ir no presente + infinitivo ("No próximo mês vou viajar para o exterior"); d) a forma perifrástica com o verbo ir no futuro + 


\begin{abstract}
infinitivo ("No próximo mês irei viajar para o exterior"); e) a forma perifrástica com o verbo haver no presente + de + infinitivo ("No próximo mês hei de viajar para o exterior"); e f) e a forma perifrástica com o verbo haver no futuro + de + infinitivo ("No próximo mês haverei de viajar para o exterior").
\end{abstract}

Nesse trabalho, Oliveira (2006) com uma perspectiva variacionista e funcionalista, analisa a norma culta do PB com base em pessoas de nível superior do Rio de Janeiro e de Salvador. A variação de futuro é analisada em tempo real (longa e curta duração) e em tempo aparente. Para a análise diacrônica, foram analisados dados da escrita dos séculos XIII ao XIX a partir de um corpus diversificado, composto por diferentes cartas e testamentos. O material do século XIII ao XVI foi recolhido no banco de dados do Projeto para a História do Português (PROHPOR), já o material do século XVII, do banco de dados da USP. Nos séculos XVIII e XIX os dados foram retirados do Projeto Nacional para a História do Português Brasileiro (PHPB-RJ). No século XX foram analisadas as décadas de 1970 e 1990 com dados da fala e da escrita, retirados do Projeto da Norma Urbana Oral Culta (NURC) e de editorias de jornais nas cidades do Rio de Janeiro e Salvador.

O principal objetivo do trabalho de Oliveira (2006) foi a compreensão da variação da expressão de futuro do PB, a fim de contribuir para a caracterização desse tempo verbal. Ao final, concluiu que o futuro simples foi a variante mais utilizada desde o século XVIII, mas atualmente seu uso decaiu, dando espaço ao IR no presente + infinitivo, uma mudança que ocorreu gradativamente. Quanto ao presente indicando futuro, a autora afirma que essa forma é utilizada em contextos específicos, concorrendo com o futuro simples e o futuro perifrástico com IR no presente + infinitivo.

Em outro estudo, Oliveira (2011) realiza uma pesquisa a partir de um corpus composto por jornais contemporâneos brasileiros e lusitanos do século XXI, a fim de comparar e verificar se o fator geográfico interfere na expressão de futuro. Segundo a autora, a forma perifrástica IR + infinitivo, embora já documentada no século XIV, só obteve espaço no século XIX passando a ser mais utilizada somente no século XX.

Para realizar a investigação, Oliveira (2011) utilizou como aparato teórico-metodológico a Sociolinguística Laboviana e observou as ocorrências da expressão de futuro verbal a partir de um público mais elitizado e um público mais popular de jornais dos dois países 
que se propôs a investigar. Verificou em qual etapa encontra-se o processo de mudança entre futuro simples e futuro perifrástico na escrita considerada padrão e quais são os fatores que atuam em cada uma das variedades - de Brasil e de Portugal.

De acordo com Oliveira (2011), o verbo IR é polissêmico, por ser um verbo de movimento em que superpõem as noções de espaço e de tempo. Devido a isso, afirma que o verbo IR é um dos mais "gramaticalizáveis" e tende a transformar-se como auxiliar quando adicionado ao verbo no infinitivo, tanto no PB quanto no Português de Portugal, o que significa que o processo de substituição da forma de futuro simples pela forma perifrástica IR no presente + infinitivo está quase conclusa no PB.

A partir das afirmações apresentadas acima sobre a expressão variável de futuro, analisamos, em nosso estudo, as formas de futuro a partir de uma amostra de escrita do PB: as cartas de leitores da revista feminina contemporânea Gloss.

\section{AS CARTAS DE LEITORAS DA REVISTA FEMININA GLOSS}

A revista Gloss, fundada em 2008, pela editora Abril, e finalizada em 2013 devido ao baixo índice de vendas, tinha como públicoalvo jovens meninas contemporâneas. De circulação nacional e com edições mensais, a revista tratava sobre dúvidas e notícias em geral a respeito de amor, sexo, beleza, famosos, moda, viagem, compras, dentre outros assuntos que despertavam interesse nas leitoras. Quanto ao perfil das jovens assinantes da Gloss, a maior parte encontrava-se na região sudeste do país, sendo a maioria de classes sociais privilegiadas.

A título de exemplo, segue abaixo uma das capas da revista, em que visualizamos sua finalidade. Com a imagem de uma atriz, a Gloss apresenta guias de compras; achados de moda e beleza; dicas para cuidar dos cabelos - seguindo o mesmo padrão de revistas destinadas às mulheres, preocupadas em atingir o universo feminino ideal: 
Figura 2: Capa da revista Gloss

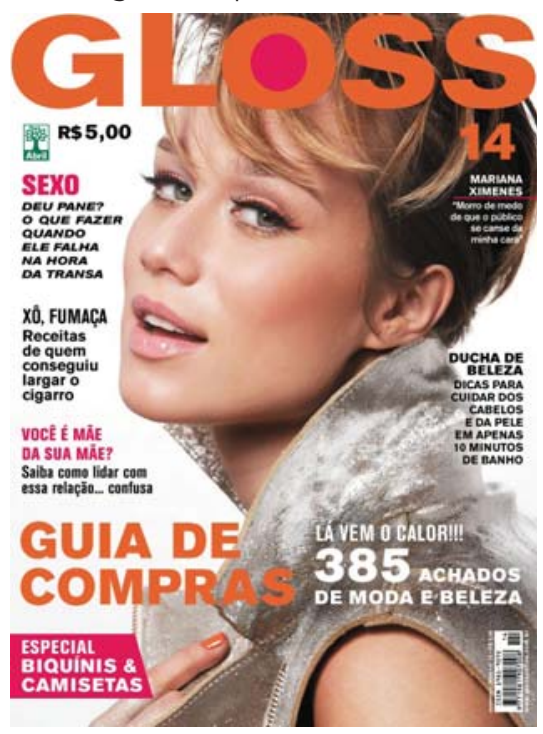

Fonte: Gloss, novembro, 2008, ed. 14

Em nossa pesquisa, atentaremos para a seção Carta do leitor , onde há uma interação entre as leitoras e a Gloss. Nela, as próprias meninas escreviam suas ideias sobre matérias de edições passadas e davam sugestões para novos assuntos a serem tratados. Ássim, o público ajudava diretamente na construção da revista, conforme observamos na imagem extraída da seção:

Figura 2: Página da revista Gloss

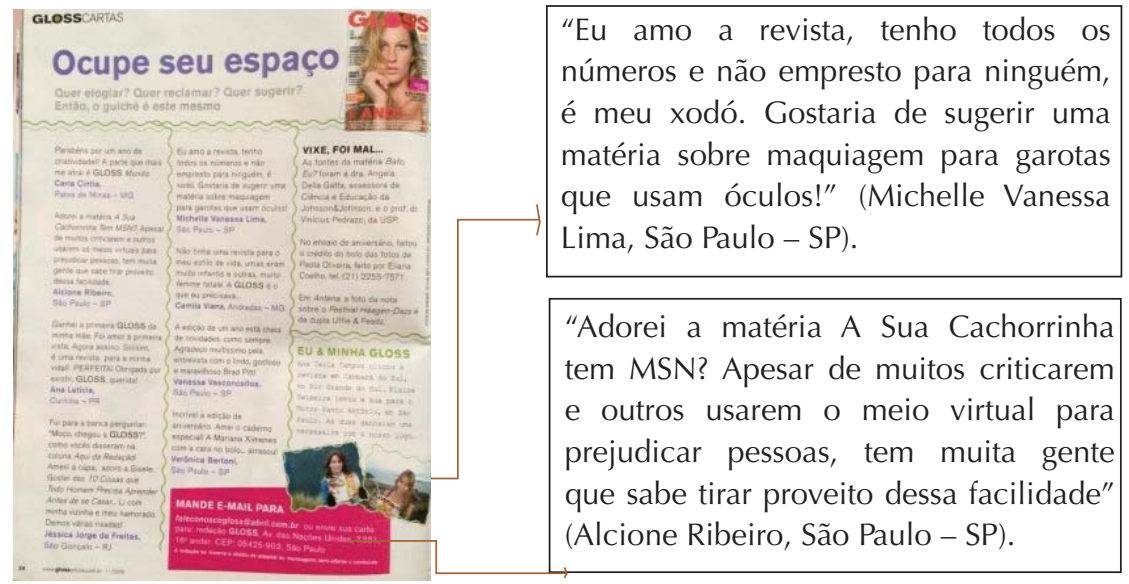

Fonte: Gloss, novembro, 2008, ed. 14, p. 24 
Vale ressaltar que, ao passar dos anos e das edições, a revista acompanhou a evolução tecnológica. Nas primeiras edições, as cartas eram enviadas por meio dos correios, nas últimas por e-mails, por um clube digital e através do facebook, permitindo maior interação entre as leitoras e a revista.

A escolha do gênero textual "carta de leitor" em nossa pesquisa se justifica por proporcionar um contexto de escrita favorável ao aparecimento de fenômenos variáveis na língua, já que "a preocupação maior do interlocutor está no que diz (conteúdo) e não no modo como diz (forma)" (MARINE; BARBOSA, 2008, p. 197)". Ainda, o gênero textual atrelado ao estudo da variação e/ou da mudança linguística pode servir como análise teórica e metodológica de textos escritos. Sobre isso, Bueno (2014, p. 22) afirma que "a busca por situações de variação e mudança em um corpus escrito nos faz reconhecer, assim como na fala, o caráter heterogêneo também da escrita, sendo essa uma tentativa de conceder à língua escrita um lugar nas pesquisas sociolinguísticas".

Marcuschi (2007) reconhece que a modalidade falada e a modalidade escrita não estão em uma relação dicotômica, fechada, mas sim em um continuum tipológico. Assim, a "carta de leitor" é caracterizada como um gênero misto, visto que possui uma linguagem aproximada ao da oralidade em que é possível visualizar traços característicos da fala de leitores. Por esse motivo, adotamos a proposta de Marine (2009) que aborda um novo tipo de modalidade intercambiária: a "língua oral-escrita". Em alguns dos trechos extraídos das cartas da revista estudada, vemos como a fala é transportada para a escrita, conforme os exemplos a seguir:

(07) Amei as 235 ideias para arrasar no verão. A cada mês a edição da GLOSS vem bombando!!! (Anna Carolinne dos Santos Lira, Paraúna - Goiás). (GLOSS, fevereiro, 2008, ed. 05, p. 18).

(08) Nossaaa, a matéria Antes de Explodir chegou na hora certa! Já estou explodindo, mas de tanta felicidade! Vou começar a respirar, respirar e respirar. Quem sabe usando essas dicas maravilhosas eu fico mais 'calminha'. (Ariane Garcia Nascimento, via email). (GLOSS, setembro, 2011, ed. 48, p. 30$)$.

(09) Achei meio exagerado falar do XVideos e do Redtube. Aquilo é mais velho que andar pra frente... (Leyla Moja). (GLOSS, julho, 2013, ed. 70, p. 16). 
No trecho (07) a palavra bombando, utilizada pela autora da carta, é uma gíria corriqueira na fala, em especiais na de adolescentes, com o valor semântico figurativo de uma ação enfaticamente boa, de impacto positivo. Em (08), a leitora utiliza Nossaaa, e transporta a fala para a escrita com a extensão da vogal A, dando-nos a sensação de empolgação, euforia naquilo que relata; da mesma forma, ao utilizar o adjetivo "calma" no diminutivo, a escrevente sugere uma conversa informal com a revista, como um bate-papo entre amigas. Observamos, no trecho (09), o uso do ditado popular mais velho que andar pra frente, transcrito na carta de uma das leitoras, que denota o sentido de algo realmente muito antigo.

Assim, o uso das cartas da revista feminina Gloss como corpus para esta pesquisa se justifica por evidenciar, como a modalidade falada, a língua em uso.

\section{PROCEDIMENTOS DE ANÁLISE DOS DADOS}

Montamos um corpus ${ }^{1}$ composto por trechos de cartas - extraídos da revista feminina Gloss. Para tanto, foi necessária uma busca em sebos a fim de realizar uma seleção de edições da revista, referentes ao ano de 2008 a 2013. Em seguida, selecionamos as diferentes formas que expressam futuro, são elas:

- ESTRUTURAS LINGUÍSTICAS UTILIZADAS NA EXPRESSÃO DA FUTURO: verificamos quais formas verbais foram utilizadas pelas adolescentes para expressar o tempo futuro, conforme exemplificamos abaixo:

(a) Forma sintética - Verbo no futuro simples:

(10) A Débora Falabella é como toda mineirinha: bem na dela. A Mel de O Clone ficará para sempre em meu coração - com essa personagem vi surgir uma grande atriz. Ah, ela ficou linda na capa de vocếs. (Danielle de Lima, pelo Clube da Leitora). (GLOSS, agosto, 2010, ed. 35, p. 22).

(b) Forma Perifrástica: Verbo IR no presente + infinitivo:

(11) Eu ainda fico com Cinquenta Tons de Cinza. Li, adorei e vou ler a trilogia toda, com certeza! (Giselle Dutra). (GLOSS, janeiro, 2013, ed. 64, p. 16).

(c) Forma Perifrástica: Verbo IR no futuro + infinitivo:

1. As revistas foram compradas por meio do site "Estante Virtual". No total, foram coletadas 50 edições da revista no período de 2008 a 2013. 
(12) Anos atrás eu era encanada com essa coisa de "arrumar um amor" (Procura-se um Namorado). Mas com o passar do tempo descobri que a melhor coisa é desencanar, deixar a vida te levar. Mais dia, menos dia, a tampa da sua panela irá aparecer. (Fernanda Hitomi Shibukawa, pelo Clube da Leitora). (GLOSS, julho, 2011, ed. 46, p. 14).

(d) Forma do presente:

(13) Moro com o meu namorado e, quando me perguntam a diferença, digo que estamos em um período de experiência, um estágio. Se passarmos nas avaliações mútuas, aí assinamos o contrato. (Vivi Lemos). (GLOSS, fevereiro, 2013, ed. 65, p. 14).

Após esta etapa, analisamos as ocorrências segundo os grupos de fatores abaixo:

- PRESENÇA/AUSÊNCIA DE ADJUNTO ADVERBIAL: O adjunto adverbial associado ao verbo pode atribuir diferentes valores semânticos na sentença. Desse modo, é de nosso interesse investigar de que maneira o verbo comporta o adjunto adverbial e se sua presença é recorrente ou não. A título de exemplo, seguem dois trechos de nosso corpus em que neste inverno e sempre configuram o valor de futuro à sentença:

(14) Estou desde o ano passado querendo a cor da Blake Lively. Neste inverno, eu faço! (Aline Moreira). (GLOSS, fevereiro, 2013, ed. 65, p. 14).

(15) Não gostei da Angélica na capa...Mas, deixando isso de lado, felizmente sei que a GLOSS sempre terá um miolo delicinha para mim, independentemente da capa. Que vontade enoooorme de abraçar a equipe de produção de moda de vocês! Cada foto é sempre divertida, bem sacada e bem produzida! (Gabriela César, São Paulo - SP). (GLOSS, maio, 2009, ed. 20, p. 16).

- MODALIDADE: O que se quer sugerir/dizer a partir de um verbo também é relevante para a nossa análise, já que o falante "ao exteriorizar um desejo através de uma forma do futuro, projeta-o adiante, implicando que sua realização será posterior ao momento da fala" e nessa exteriorização "projeta uma variedade de noções modais: volição, obrigação [...]" (SILVA, 1997, p. 62). Assim, faz-se necessário atentarmos aos valores modais do verbo, primordialmente à: 
(a) Possibilidade: "Referem-se ao eixo da existência e à verdade ou falsidade de estado das coisas. Em outras palavras, expressam a atitude do falante quanto ao valor de verdade de seus enunciados" (SILVA, 2002, p. 5657).

(16) Penso assim: 'O que já não é mais seu pode ser de alguém!' Meu ex namora uma das minhas amigas, e não vejo problema. Quem sabe eles não serão feliz para sempre?!? (Anna Carolina Martins, pelo Clube da Leitora). (GLOSS, setembro, 2010, ed. 36, p. 30).

(b) Certeza: "Referem-se ao conhecimento (crença) que se tem de um estado de coisas. Tem a ver com o grau de conhecimento e certeza do falante a respeito da fatualidade daquilo que está dizendo" (SILVA, 2002, p. 57).

(17) Vou fazer parecido com o da Lea Michele. Estou louca para sair do preto básico e ficar mais fashion. (Grazielly Cento). (GLOSS, fevereiro, 2013, ed. 65, p. 14).

(c) Desejo/ Solicitação: "Estão ligadas à vontade, ao desejo e à emotividade do falante, fazendo com que o evento, muitas vezes, se realize" (SILVA, 2002, p. 58).

(18) Adorei a Taís Araújo na capa da GLOSS! Desde o ano passado que queria vê-la na revista. Ah, como ela é linda! Amei a make dela! E quero sugerir matérias com dicas para descolar peças bacanas em brechós. Como garimpar, trocar, vender... (Deise Matos, São Paulo SP). (GLOSS, junho 2009, ed. 21, p. 18).

Após a seleção e codificação dos dados, analisamos qualitativamente os resultados, a partir da teoria variacionista que embasa este artigo.

\section{ANÁLISE DOS DADOS}

Ao selecionarmos as ocorrências verbais que expressavam futuro nas cartas das leitoras da revista Gloss, chegamos a um total de 52 formas, assim distribuídas: 
Tabela 1: Resultados gerais

\begin{tabular}{|c|c|c|}
\hline FORMAS DE FUTURO & $\begin{array}{l}N^{\circ} \text { DE OCORRÊN- } \\
\text { CIAS }\end{array}$ & PORCENTAGEM \% \\
\hline $\begin{array}{l}\text { Forma sintética: verbo } \\
\text { no futuro simples }\end{array}$ & 9 & $17,3 \%$ \\
\hline $\begin{array}{l}\text { Forma perifrástica: } \\
\text { verbo IR no presente + } \\
\text { infinitivo }\end{array}$ & 22 & $42,4 \%$ \\
\hline $\begin{array}{l}\text { Forma perifrástica: } \\
\text { verbo IR no futuro + } \\
\text { infinitivo }\end{array}$ & 3 & $5,7 \%$ \\
\hline Forma do presente & 18 & $34,6 \%$ \\
\hline TOTAL & 52 & $100 \%$ \\
\hline
\end{tabular}

Observamos, na Tabela 1, que a forma perifrástica IR no futuro + infinitivo é a que apresenta menor incidência, com apenas 3 ocorrências $(5,7 \%$ do total), mostrando-se pouco produtiva entre as escreventes das cartas da revista Gloss. Vejamos uma das sentenças em que aparece esta forma:

(19) Anos atrás eu era encanada com essa coisa de 'arrumar um amor' (Procura-se um Namorado). Mas com o passar do tempo descobri que a melhor coisa é desencanar, deixar a vida te levar. Mais dia, menos dia, a tampa da sua panela irá aparecer. (Fernanda Hitomi Shibukawa, pelo Clube da Leitora). (GLOSS, julho, 2011, ed. 46, p. 14).

No exemplo, a leitora utiliza a perífrase IR no futuro + infinitivo para atribuir o sentido de um futuro distante, mas possível de ser consolidado; o que é comprovado ao lermos inteiramente a sentença, em que a adolescente escreve sobre suas frustações em relação a um amor que não teve no passado e nem encontrou no presente, mas almeja achá-lo no tempo futuro. Identificamos também que o valor de futuro é enfatizado por meio da presença de adjunto: "mais dia, menos dia", expressão que acarreta a noção de algo esperado, desejado, de uma passagem de tempo, de dias. Vale ressaltar que a forma perifrástica IR no futuro + infinitivo, em nosso corpus, acompanhava adjuntos adverbiais e expressava a modalidade de possibilidade/dúvida. 
As leitoras da revista Gloss utilizam outras estruturas linguísticas para expressar futuro, como observamos nos demais resultados. Ainda no Tabela 1, verificamos - conforme já apontado em outras pesquisas, como a de Silva (2002) - que o Futuro do Presente do Indicativo (forma sintética) também é pouco utilizado, empregado apenas em 9 ocorrências $(17,3 \%$ do total) dos dados. Diferentemente do que prescreve as GT's, o Futuro do Presente do Indicativo tem sido pouco produtivo no PB contemporâneo e seu uso é restrito a contextos muito específicos, incidindo em textos altamente formais de teor preditivo ou injuntivo (cf. SILVA 2002, OLIVEIRA 2006, BARBOSA 2007).

Entre os poucos casos que as leitoras utilizaram o futuro simples, destacamos os exemplos:

(20) Parabéns pela iniciativa de utilizar as mudanças ortográficas da língua portuguesa na primeira revista de 2009. Não podia de deixar de parabenizá-los. Sou professora de língua portuguesa e acho que isso nos ajudará a fixar a nova regra. (Nivia Natalense, Fortaleza - CE). (GLOSS, fevereiro, 2009, ed. 17, p. 16).

(21) Sempre adorei os textos da Sílvia Amélia e fiquei feliz de saber que ela terá um blog no site de GLOSS! (Poliana Sousa). (GLOSS, julho, 2013, ed. 70, p. 17).

(22) Farei mamoplastia de redução no fim do ano e a reportagem de GLOSS sobre plástica veio a calhar. Adorei a dica de pesquisar se o médico tem registro na Sociedade Brasileira de Cirurgia Plástica, algo que a maioria das pessoas esquece. (Denise Suenaga). (GLOSS, outubro, 2012, ed. 61, p. 26).

Nos trechos, as escreventes utilizam a forma sintética dos verbos ajudar, ter e fazer. Acreditamos que as leitoras preferiram o uso dessa forma para transmitir à revista e, consequentemente, ao público alvo em geral, maior credibilidade ao que escreveram. Os verbos no futuro simples, em nosso corpus, atestaram a certeza de um evento consolidarse e, na grande maioria das ocorrências, não acompanharam adjuntos adverbiais, fato que pode ser explicado, já que o verbo transmite morfologicamente a noção de futuro para o evento.

Vemos que, apesar da expressão do futuro aparecer por meio do emprego da forma sintética, no material analisado essa forma não é a recorrente. No contexto em que o gênero textual "carta de leitor" está inserido, como já elucidado, a linguagem escrita pelos locutores se 
aproxima a um contexto mais informal, principalmente por constituirse como uma conversa entre amigas, cujo o principal objetivo é trocar experiências e novas ideias para a revista, ou seja, o conteúdo torna-se mais relevante do que a forma.

As gramáticas e os materiais didáticos designam o Futuro do Presente do Indicativo como a forma que prevalece para expressar eventos posteriores ao MF. A afirmação é verificada em Pasquale Cipro e Ulisses Infante (2010, p. 129), quando se referem à flexão de tempo:

No momento em que se fala ou escreve, o processo verbal pode estar em plena ocorrência, pode já estar concluído ou pode ainda não ter ocorrido. Essas três possibilidades básicas, mas não únicas, são expressas pelos três tempos verbais: o presente, o pretérito (que pode ser perfeito, imperfeito ou mais-que-perfeito) e o futuro (que pode ser do presente ou do pretérito) [...].

Apesar dos autores apontarem que as formas apresentadas "não são as únicas", não é indicada outras formas, o que leva o leitor a inferir que a mais utilizada, no caso do tempo futuro, é o Futuro do Presente do Indicativo. Em contrapartida, na análise de nosso corpus, a perífrase IR no presente + infinitivo é a mais produtiva na escrita das leitoras, a confirmação do que é prescrito nas GT's não ocorreu, portanto.

Como mencionado em outras seções, estudos atestam que o futuro simples está gradativamente sendo substituído pela perífrase IR no presente + infinitivo. Oliveira (2011), por exemplo, argumenta que, na escrita, a forma perifrástica vem sofrendo um processo ao longo dos anos, sendo documentada desde o século XIV e adquirindo espaço e reconhecimento a partir do século XX. Na fala, Silva (2002) afirma que os falantes utilizam IR no presente + infinitivo para expressar tempo futuro em contextos espontâneos. De fato, as considerações dos estudos são observadas em nossa pesquisa, como nos exemplos abaixo:

(23) Eu ainda fico com Cinquenta Tons de Cinza. Li, adorei e vou ler a trilogia toda, com certeza! (Giselle Dutra). (GLOSS, janeiro, 2013, ed. 64, p. 16).

(24) Vou pintar o cabelo igual ao da Giovanna Antonelli. Ela está linda! (Juliana Oliveira). (GLOSS, fevereiro, 2013, ed. 65, p. 14).

(25) Estou fazendo isso este ano. Não curti minha primeira faculdade, trabalho na mesma área há seis anos e finalmente vou fazer o curso que me apaixona. 
Estou morta de medo, mas intensamente animada! (Rach Morais). (GLOSS, março, 2013, ed. 66, p. 22).

Como ilustrado acima e verificado na Tabela 1, 42,4\% das expressões de futuro nas cartas da revista Gloss apareceram com a perífrase IR no presente + infinitivo. Nos exemplos (23-25) as leitoras participam de uma conversa sem qualquer tipo de formalidade, em que o interlocutor é a própria revista Gloss. É a partir da espontaneidade que o assunto se forma e que as meninas escrevem vou ler, vou pintar e vou fazer, em lugar de lerei, pintarei e farei.

Mesmo que de forma indireta, os usuários da língua utilizam a forma perifrástica IR no presente + infinitivo, como já apontado por Silva (2002), para demarcar a relevância do presente na realização do evento futuro, como no exemplo (23) em que a leitora se refere a um livro e, a partir do entusiasmo adquirido pela obra no tempo presente, o evento futuro é determinado. Assim acontece nos demais trechos, em (24) por gostar da atual (até então) tintura do cabelo de uma atriz, a leitora sente-se motivada e quer imitá-la no futuro; em (25) a garota relata sobre suas frustrações tanto na área acadêmica quanto na profissional e, a partir de suas emoções do tempo presente, a leitora opta por fazer algo, no evento futuro, que se identifique mais. Destacamos que a perífrase IR no presente + Infinitivo, em nosso corpus, expressava certeza e o uso dos adjuntos adverbiais, nessa amostra, não foi recorrente.

Como observamos nos resultados gerais, o Presente do Indicativo também foi produtivo entre as leitoras, já que 18 das ocorrências (34, 6\% do total) apareceram expressando futuro. Associado à ênfase, certeza ou a um acontecimento próximo, o tempo presente é mencionado em algumas GT'S, como em Bechara (2009), mas não é apresentado como possível de expressar futuro. De acordo com Oliveira (2006, p. 174), "o presente do indicativo é um tempo verbal não-marcado morfologicamente", ou seja, "é necessário que haja um determinado contexto de futuro para que o presente possa ser empregado com esse valor".

Portanto, para melhor entendermos esse fenômeno, verificamos se as ocorrências apareciam como verbo auxiliar modal ou como verbo principal: 
Tabela 2: Presente do Indicativo com valor de futuro

\begin{tabular}{|c|c|c|}
\hline $\begin{array}{c}\text { VERBO NO } \\
\text { PRESENTE }\end{array}$ & No DE OCORRÊNCIAS & PORCENTAGEM \% \\
\hline Auxiliar modal & 8 & $44,5 \%$ \\
\hline Principal & 10 & $55,5 \%$ \\
\hline TOTAL & 18 & $100 \%$ \\
\hline
\end{tabular}

Na Tabela 2, os verbos se dividiram, quase igualmente, nas duas categorias escolhidas. Assim, em nosso corpus, quando empregada a forma do presente com valor de prospecção (futuro), $44.5 \%$ dos casos ocorreu com verbo auxiliar e 55,5\% com o verbo como principal, geralmente acompanhados de adjunto adverbial e com o valor de "desejo/solicitação". Essa situação é exemplificada a seguir, com dados retirados da amostra²:

(26) Sugeri uma matéria sobre a tiroide e fui atendida. Agora espero para breve uma reportagem especial sobre hidroginástica. Ah, e a capa ficou demais... (Fabiane Kohuth, Ibirama - SC). (GLOSS, fevereiro, 2009, ed. 17, p. 16).

(27) Eu gostaria de agradecer pela matéria sobre intercambio. Quero viajar no próximo ano, e saber que alguns países concedem bolsas de estudos me deixou muito feliz. Obrigada pela ótima informação! (Fernanda Santos, via email). (GLOSS, novembro, 2011, ed. 50, p. 28).

No trecho (26) a leitora utiliza o verbo principal esperar com valor modal de desejo: esperar uma reportagem especial sobre hidroginástica. Com este valor semântico, o verbo expressa futuro devido ao contexto em que está inserido. O adjunto "agora" é associado à "para breve", ou seja, a leitora o utiliza, somado ao verbo, para expressar a ideia de espera a curto prazo, remetendo-nos a um evento que acontece no presente, mas tem extensão no futuro.

Em (27) o verbo auxiliar querer no presente também funciona como verbo modal expressando um desejo da leitora: o de viajar no próximo ano. Os verbos auxiliares modais, em nosso corpus, quando no presente, foram ou não acompanhados de adjuntos, mas mesmo que

2. Os verbos modais e principais no Presente do Indicativo encontram-se em itálico; já os adjuntos adverbiais encontram-se sublinhados. 
não, pudemos inferir a expressão de futuro por meio da modalidade, diferentemente do verbo principal que necessitou da presença de adjunto adverbial ou da análise do contexto discursivo para que o valor temporal futuro fosse atribuído.

Em alguns casos específicos das ocorrências destoaram dos demais, como os exemplos:

(28) A-do-rei a matéria de moda das sandálias pesadas com meias! Uma graça e dá para substituir botinhas, no caso de quem mora em lugares quentes, como eu. (Graziela Raton, Salvador- BA). (GLOSS, julho 2009, ed. 22 , p. 20).

(29) Eu acho que, se o relacionamento terminou bem, sem mágoas, dá para manter a amizade sim! (Bruna Dias). (GLOSS, abril, 2012, ed. 55, p. 30).

Nesse sentido, aludimos aos pensamentos de Benveniste (2006 [1989]) quando se refere à noção do tempo linguístico. O linguista afirma que o tempo presente (Presente do Indicativo) se posiciona como ponto central, ou seja, relaciona-se com os demais tempos (passado e futuro) no ato linguístico, norteando as experiências dos falantes da língua.

Nos trechos, o verbo dar é utilizado pelas leitoras para se referirem a assuntos das matérias da revista em diferentes edições. Nos dois trechos, os verbos expressam uma possibilidade de um evento; em (28) a leitora comenta sobre a possível mudança de sapatos, em específico de botinhas; já em (29) a leitora relata sobre a possibilidade de fazer o relacionamento amoroso, que não deu certo, tornar-se amizade.

Por se tratar de um evento possível, consideramos que as ocorrências com o verbo dar, em determinados casos como os apresentados, contribuem para a expressão de futuro nas sentenças. Como propõe Benveniste (2006 [1989]), verificamos que o presente é o eixo para posicionar os demais tempos, no caso em específico o futuro.

\section{CONSIDERAÇÕES FINAIS}

A partir dos resultados desta pesquisa, concluímos que a expressão de futuro no PB é um fenômeno em variação, observado também em amostras de escrita, já que encontramos várias formas que coocorrem para expressar o valor temporal futuro: forma sintética - 
futuro simples; forma perifrástica - verbo IR no presente + infinitivo; forma perifrástica - verbo IR no futuro + infinitivo; e forma do presente.

Vários estudos têm apontado a implementação da forma perifrástica IR no presente + infinitivo como possível substituta da forma sintética (futuro simples). De fato, a perífrase mencionada mostrou-se a mais produtiva entre as leitoras escreventes da revista Gloss. Além disso, encontramos casos de expressão do futuro com verbos conjugados no Presente do Indicativo, expressando futuro, em determinados contextos, ora como auxiliar modal ou ora como verbo principal.

Em relação à modalidade, verificamos que as formas de futuro analisadas expressam certeza, possibilidade ou desejo/solicitação e transitem a noção de futuro para as sentenças analisadas.

Vimos que, o processo de substituição (futuro simples < perífrase IR no presente + infinitivo) está em fase avançada de variação, pois já é observada na modalidade escrita em determinados contextos, como o que investigamos. Desse modo, verificar o conjunto de fatores linguísticos que condicionam as maneiras alternativas de expressar futuro é relevante para o levantamento de descrições socio(linguísticas) sobre o PB na modalidade escrita da língua.

\section{REFERÊNCIAS BIBLIOGRÁFICAS}

BARBOSA, J. B. A expressão do futuro no português brasileiro contemporâneo. Revista Eletrônica do Instituto de Humanidades, volume VI, número XXIII, p. 42- 50, 2007.

Tenho feito/Fiz a tese: Uma proposta de caracterização do pretérito perfeito no Português. 282 f. Tese (Doutorado em Linguística e Língua Portuguesa) -Universidade Estadual Paulista, Faculdade de Ciências e Letras, Campus de Araraquara, 2008.

BECHARA, E. Moderna Gramática Portuguesa. 37. ed. Rev. ampl. E atual. Conforme o novo Acordo Ortográfico. Rio de Janeiro, Nova Fronteira, 2009.

BENVENISTE, É. A linguagem e a experiência humana. Problemas de linguística geral II. Tradução de Eduardo Guimarães et al.; revisão técnica da tradução Eduardo Guimarães. 4. ed. Campinas, Pontes, 2006.

BUENO, L. C. de O. Variação e gênero textual: $O$ uso das preposições nas cartas de leitoras brasileiras e portuguesas. Dissertação (Mestrado em Linguística e Língua Portuguesa) - Universidade Estadual Paulista, Faculdade de Ciências e Letras, Campus Araraquara, 2014. 
CEGAllA, D. P. Novíssima Gramática da Língua Portuguesa. 48. ed. São Paulo, Companhia Editora Nacional, 2008.

CORÔA, M. L. M. S. O tempo nos verbos do português. São Paulo, Parábola Editorial, 2005.

CUNHA, C.; CINTRA, L. Nova Gramática do Português Contemporâneo. 3. ed. Rio de Janeiro, Nova Fronteira, 2001.

LABOV, W. Padrões Sociolinguísticos. Tradução de Marcos Bagno, Maria Marta Pereira Scherre, Caroline Rodrigues Cargoso. São Paulo, Parábola Editorial, 2008.

MARCUSCHI, L. A. Da fala para a escrita: atividades de recontextualização. 8. ed. São Paulo, Cortez, 2007.

MARINE, T. de C.; BARBOSA, J. B. Gostava que fizessem este exercício. - Gostava ou gostaria?. Estudos Linguísticos, v. 37, n. 1, p. 193-202, jan. abr/ 2008.

MARINE, T. de C. Um estudo sócio-discursivo do sistema pronominal dos demonstrativos no Português Contemporâneo. 220 f. Tese (Doutorado em Linguística e Língua Portuguesa) - Universidade Estadual Paulista, Faculdade de Ciências e Letras, Campus de Araraquara, 2009.

OLIVEIRA, J. M. de. O futuro da língua portuguesa ontem e hoje: variação e mudança. 252 f. Tese (Doutorado em Língua Portuguesa) - Universidade Federal do Rio de Janeiro, Faculdade de Letras, Rio de Janeiro, 2006.

A expressão variável do futuro verbal na escrita: Brasil e Portugal em confronto. Revista da ABRALIN, v. Eletrônico, n. Especial, p. 367-383. $1^{a}$ parte 2011.

PASQuAle, C. N.; INFANTE, U. Gramática da Língua Portuguesa. 3 ed. São Paulo, Scipione, 2010.

SILVA, A. da. A expressão da futuridade no português falado. Tese (Doutorado em Linguística) - Instituto de Estudos da Linguagem, Universidade Estadual de Campinas. Campinas, 1997.

A expressão da futuridade no português falado. Araraquara: UNESP, $F C L$, Laboratório Editorial; São Paulo, Cultura Acadêmica Editora, 2002.

Recebido em: 28/06/2018

Aceito em: 20/11/2018 